\title{
Reversed Intestinal Rotation with Annular Pancreas Presented as Acute Necrotizing Pancreatitis- A Case report
}

\author{
Byshetty Rajendar ${ }^{*}$, Shanmugam $\mathrm{D}^{1}$, Kadambari $\mathrm{D}^{1}$ and Sravani Thammishetti ${ }^{2}$ \\ ${ }^{1}$ Department of General surgery, JIPMER, India \\ ${ }^{2}$ Department of Radiology, JIPMER, India
}

Submission: April 29, 2020; Published: June 08, 2020

*Corresponding author: Byshetty Rajendar, Senior Resident, Department of General surgery, JIPMER, Pondicherry, India

Keywords: Acute necrotizing pancreatitis; Intestinal rotational abnormalities; Tachypnea; Tachycardia; Liver enzymes; Serum calcium; Triglyceride; Intravenous fluids; Analagesics; Antiemetics

\section{Introduction}

Reversed intestinal rotation (RIR) is a rarest form of the intestinal rotational abnormalities [1]. Annular pancreas is also a rare congenital anomaly which can be associated with intestinal malrotation [2]. Annular pancreas presents rarely with duodenal obstruction, pancreatitis and peptic ulceration in adults [3]. Only a few cases of pancreatitis related to an annular pancreas have previously been reported. This is the first case report of annular pancreas associated with intestinal malrotation, presenting as acute necrotizing pancreatitis in an adult.

\section{Case Report}

A 45 years old female presented to the Emergency Room with complaints of upper abdominal pain associated with vomiting for 3 days. She had continuous, throbbing pain in the epigastric and left hypochondrial region. It was associated with bilious vomiting. She also had abdominal distention. She did not have fever or decreased urine output. She was non-alcoholic. She had no history of drug intake for any medical illness. On examination she was conscious, afebrile, dehydrated. She had tachypnea and tachycardia. Her abdomen was tense with diffuse tenderness and guarding. Bowel sounds were normal. She was resuscitated with IV fluids in emergency room.

Initial investigations revealed serum amylase 956 IU/L. Her liver enzymes, serum calcium, triglyceride levels were within normal limits. Abdominal ultrasound revealed minimal free fluid abdomen. Pancreas was obscured by bowel gas, gall bladder and common bile duct were normal. CT abdomen demonstrated diffusely enlarged pancreas with shaggy contour and nonenhancing pancreas for more than $30 \%$ in the head and proximal body region (Figure 1). Modified CT Severity Index (CTSI) was 8, suggestive of Acute severe Pancreatitis. There was part of the head noted on the right of the second part of duodenum which was continuous with the rest of the pancreas suggestive of Annular Pancreas (Figure 2). The third part of the duodenum was seen anterior to the superior mesenteric artery and transverse colon found to be behind the SMA (Figure 3). The hepatic flexure, ascending colon and caecum were seen in the right iliac fossa due to non fixation, consistent with reverse rotation of the intestine (Figure 4). There were no signs suggestive of pancreatic infection.

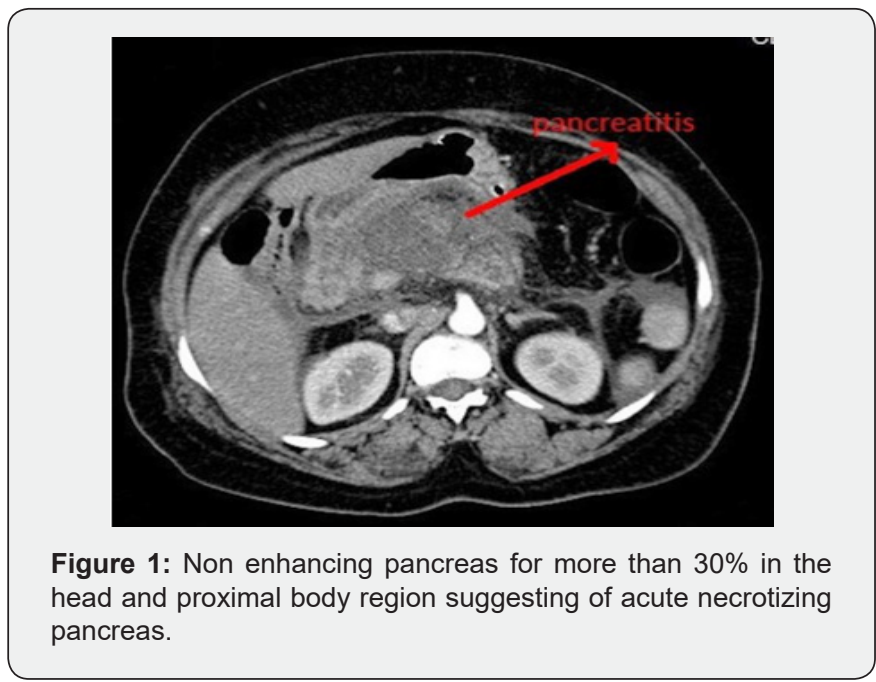




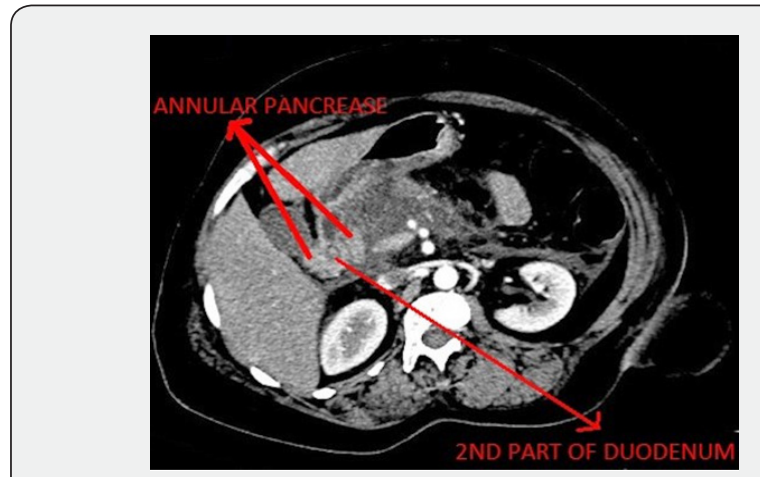

Figure 2: Part of the head noted on the right side of second part of the duodenum which was continuous with the rest of the pancreas suggestive of annular pancreas.
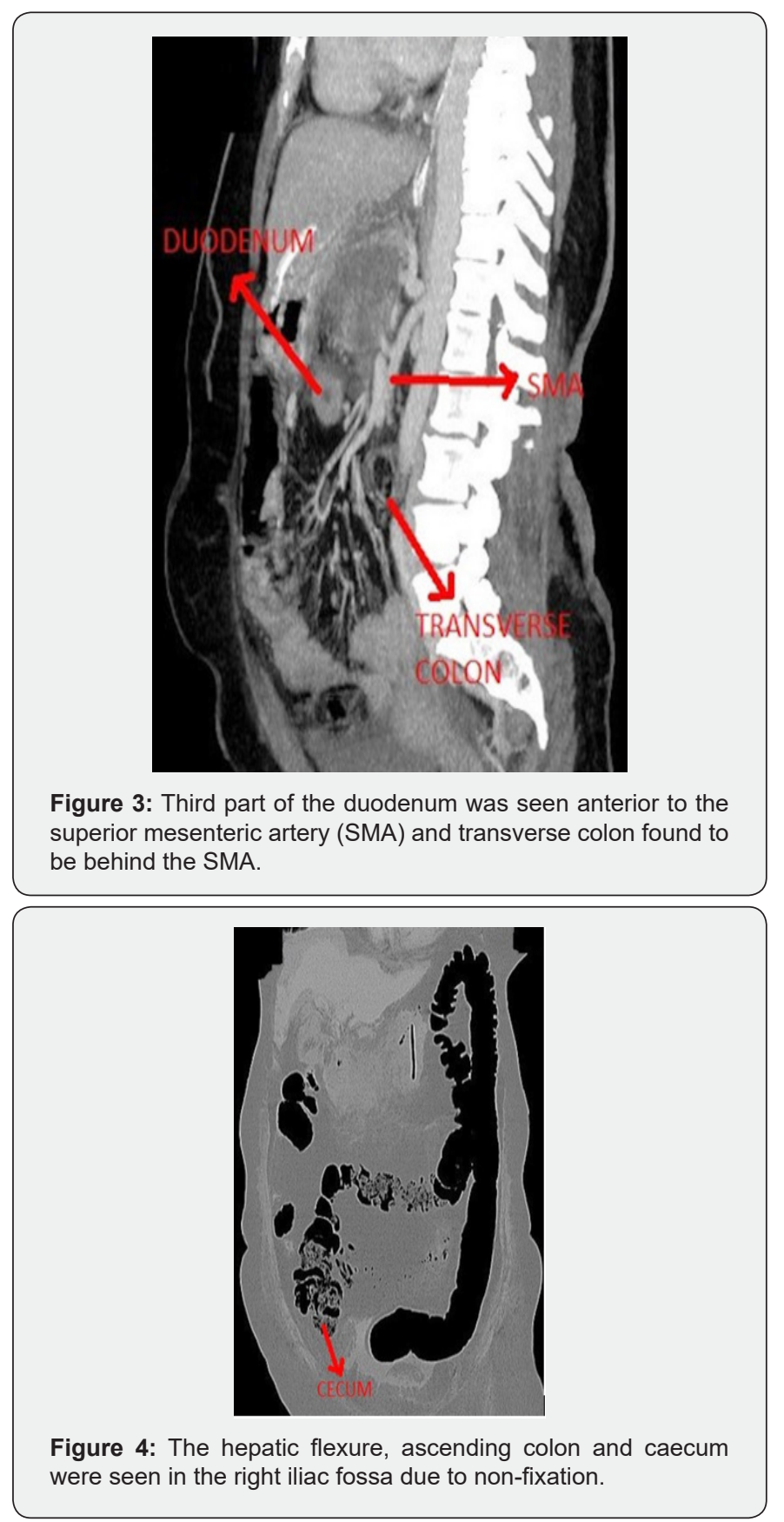

The patient responded to conservative management with intravenous fluids, analagesics and antiemetics. She was gradually started on orals on day 3 and was discharged on day 7 .

\section{Discussion}

RIR is rarest of all rotational abnormalities of the intestine, representing approximately $2-4 \%$ of reported cases of malrotation [1]. RIR is due to error in the second stage of midgut rotation. In this anomaly, the gut rotates $90^{\circ}$ in a clockwise direction around the axis of the superior mesenteric artery instead of $270^{\circ}$ in an anticlockwise direction such that the transverse colon moves to the right behind the superior mesenteric vessels and the duodenum lies anterior to the colon [4]. The rest of the bowel can occupy a normal position but its visceral surface is reversed.

Congenital anomalies of the intestinal rotation are seen commonly in infancy and childhood. They may present with volvulus of the ileocecal segment due to its narrow mesenteric attachment, large bowel obstruction at the retroarterial segment of transverse colon and rarely small bowel obstruction at the duodenojejunal junction by periduodenal bands [5]. They are uncommon in adults and majority of the cases are usually asymptomatic [6,7]. But some patients may present with chronic unexplained and atypical symptoms like vague abdominal pain and weight loss, while very few may experience an acute episode of duodenal or intestinal obstruction [8]. Our patient was asymptomatic until she presented with acute severe pancreatitis.

Annular pancreas, a pancreatic fusion anomaly, has an incidence of approximately $0.005 \%$ [9]. During development of pancreas, ventral bud rotates and passes behind the duodenum from right to left and fuses with the dorsal bud to form the inferior part of the uncinate process and part of the head of pancreas, whereas the dorsal bud gives rise to the tail and the body. Fusion of the ducts of the two buds produces the main pancreatic duct. Annular pancreas results from failure of the ventral bud to rotate with the duodenum, resulting in envelopment of the duodenum [10].

Annular pancreas presentation has a bimodal distribution, the first peak is in infancy and the second one in the fourth decade of life. Peadiatric cases usually present with intestinal obstruction or associated anomalies. Associated conditions include mongolism, intestinal malrotations, duodenal atresia or webs, tracheoesophageal fistulas and cardiac defects [11]. Between one half to two thirds of cases of annular pancreas in adults remain asymptomatic. Adult annular pancreas is associated with duodenal obstruction (60\%), pancreatitis (15-50\%) and peptic ulceration (26-48\%) [3].

Pancreatitis due to annular pancreas generally involves the annulus and the adjoining pancreatic head, preserving the body and tail of the gland [12]. This is probably attributed to inability of pancreatic secretions to flow through the Santorini duct, where as the main pancreatic duct allows the flow of secretions from the body and tail of the pancreas to remain intact [13]. This patient 
had $30 \%$ necrosis of head and proximal body which corresponds to the above explanation.

The diagnosis is most likely of exclusion after eliminating other common causes of pancreatitis. The related inflammation of the annulus may cause an obstruction of the encircled duodenum. CT showed edema of the annulus which might be the reason for episodes of bilious vomiting in our patient. The patients usually respond well to medical treatment as in our case. Pancreaticoduodenectomy has been recommended only when anannular pancreas is associated with pancreaticolithiasis complicated by chronic pancreatitis which might warrant further follow-up to look for progression of the disease [14].

\section{Conclusion}

RIR, though a very rare anomaly, is usually asymptomatic unless complicated by volvulus or internal herniation. An intestinal anomaly detected is usually associated with other anomalies like pancreatic fusion anomaly among others, so a thorough evaluation of these patients is warranted. The presentation of these anomalies can vary across a spectrum: from being asymptomatic to presenting with acute severe pancreatitis or intestinal obstruction due to Annular Pancreas. Malrotation of the gut has been associated with the above condition but is usually an incidental finding in adults. A combination of reverse intestinal rotation with annular pancreas is yet unreported in adults to our knowledge and the possibility needs to be considered by Gastroenterologists.

\section{References}

1. Scobie WG (1969) A case of reversed rotation presenting as duodenal ileus. Br J Surg 56(9): 709-711.
2. Raman VS, Arora M, Khanna SK (2015) Annular pancreas, type I choledochal cyst and malrotation in a low-birth weight newborn: A case report. J Indian Assoc Pediatr Surg 20(3): 155-156.

3. Urayama S, Kozarek R, Ball T, J Brandabur, L Traverso, et al. (1995) Presentation and treatment of annular pancreas in an adult population. Am J Gastroenterol 90(6): 995-999.

4. Res JR, Redo SF (1968) Anomalies of intestinal rotation and fixation. Am J Surg 116(6): 834-841.

5. Nehra D, Zeineh M, Rodriguez F, Dutta S (2007) Double reverse intestinal malrotation: a novel rotational anomaly and its surgical correction. J Pediatr Surg 42(3): 578-581.

6. (2003) Adult malrotation: a case report and review of the literature. Gamblin TC, Stephens RE Jr, Johnson RK, Rothwell M (Edt.), Curr Surg 60: 517-520.

7. Bhatia S, Jain S, Singh CB, Bains L, Kaushik R, et al. (2018) Malrotation of the Gut in Adults: An Often Forgotten Entity. Cureus 10(3): e2313.

8. Wang CA, Welch CE (1963) Anomalies of intestinal rotation in adolescents and adults. Surgery 839-855.

9. Paraskevas G, Papaziogas B, Lazaridis C, Gigis P, Papaziogas T (2001) Annular pancreas in adults: embryological development, morphology and clinical significance. Surg Radiol Anat SRA 23(6): 437-442.

10. Dowsett JF, Rode J, Russell RC (1989) Annular pancreas: a clinical, endoscopic, and immunohistochemical study. Gut 30(1): 130-135.

11. Kiernan PD, ReMine SG, Kiernan PC, ReMine WH (1980) Annular pancreas: May Clinic experience from 1957 to 1976 with review of the literature. Arch Surg 115(1): 46-50.

12. Itoh Y, Hada T, Terano A, Itai Y, Harada T (1989) Pancreatitis in the annulus of annular pancreas demonstrated by the combined use of computed tomography and endoscopic retrograde cholangiopancreatography. Am J Gastroenterol 84(8): 961-964.

13. Drey NW (1957) Symptomatic annular pancreas in the adult. Ann Intern Med 46(4): 750-772.

14. Chen YC, Yeh CN, Tseng JH (2003) Symptomatic adult annular pancreas. J Clin Gastroenterol 36(5): 446-450.

\section{Your next submission with JuniperPublishers will reach you the below assets}

- Quality Editorial service

- Swift Peer Review

- Reprints availability

- E-prints Service

- Manuscript Podcast for convenient understanding

- Global attainment for your research

- Manuscript accessibility in different formats

( Pdf, E-pub, Full Text, audio)

- Unceasing customer service

Track the below URL for one-step submission https://juniperpublishers.com/online-submission.php 